\title{
Sand-fly saliva-Leishmania-man: the trigger trio
}

\author{
Fabiano Oliveira ${ }^{1}$, Augusto M. de Carvalho ${ }^{2}$ and Camila I. de Oliveira ${ }^{2,3}$ * \\ ${ }^{1}$ Vector Biology Section, Laboratory of Malaria and Vector Research, National Institute of Allergy and Infectious Diseases, National Institutes of Health, Rockville, \\ MD, USA \\ ${ }^{2}$ Laboratório de Imunoparasitologia, Centro de Pesquisas Gonçalo Moniz, FIOCRUZ, Salvador, Brazil \\ ${ }^{3}$ Instituto Nacional de Ciência e Tecnologia de Investigação em Imunologia (iii-INCT), Salvador, Brazil
}

\section{Edited by:}

Sukanya Narasimhan, Yale University

School of Medicine, USA

Reviewed by:

Emilio Luis Malchiodi, University of

Buenos Aires, Argentina

Yang O. Zhao, Howard Hughes

Medical Institute, USA; Yale

University, USA

*Correspondence:

Camila I. de Oliveira, Laboratório de

Imunoparasitologia, Centro de

Pesquisas Gonçalo Moniz, FIOCRUZ,

Rua Waldemar Falcão, 121 Candeal,

Salvador 40196-710, Brazil

e-mail:camila@bahia.fiocruz.br
Leishmaniases are worldwide diseases transmitted to the vertebrate host by the bite of an infected sand-fly. Sand-fly biting and parasite inoculation are accompanied by the injection of salivary molecules, whose immunomodulatory properties are actively being studied. This mini review focuses on how the interactions between sand-fly saliva and the immune system may shape the outcome of infection, given its immunomodulatory properties, in experimental models and in the endemic area. Additionally, we approach the recent contributions regarding the identification of individual salivary components and how these are currently being considered as additional components of a vaccine against leishmaniasis.

Keywords: sand-fly, saliva, Leishmania, vaccine, leishmaniasis

\section{BACKGROUND}

Leishmaniases are a widespread group of diseases caused by Leishmania protozoa. Clinical manifestations range from skin ulcers to fatal visceral disease (Table 1). Leishmania parasites are injected into the vertebrate host upon sand-fly biting and take up permanent residence within macrophages, where they replicate and cause disease. At the moment of parasite inoculation, the vertebrate host is simultaneously injected with sand-fly saliva, which causes vasodilation, prevents blood clotting (1), and host hemostasis. This facilitates blood feeding, ultimately needed for egg maturation; however, salivary molecules also modulate the vertebrate host's immune response. This mini review describes the immunomodulatory properties of sand-fly saliva and how they play on Leishmania infection, contributing to the outcome of infection and, in parallel, suggesting intervention strategies such as vaccination. Moreover, high-throughput methodologies have enabled a precise description of salivary gland transcriptomes or "sialomes." We also describe some of these molecules and their distribution within different sand-fly species.

\section{SALIVARY COMPONENTS MODULATE THE IMMUNE SYSTEM}

In the late 1980s, early 90s, studies showed that co-inoculation of Lutzomyia longipalpis sand-fly salivary gland sonicate (SGS), employed as surrogate of sand-fly salivary components, enhanced experimental infection by Leishmania sp. parasites $(2,3)$. SGS from Phlebotomus duboscqi, a vector for Leishmania major, was chemoattractive for mouse monocytes (4) whereas SGS from Phlebotomus papatasi, another vector of $L$. major, inhibited macrophage activation by IFN- $\gamma(5)$ and downregulated Inducible Nitric Oxide Synthase (iNOS) expression, thereby reducing NO production in murine macrophages (6). These results imply that
Leishmania parasites exploit these effects to ascertain survival within infected host cells.

Belkaid et al. (7) developed a "natural model" of infection in which co-inoculation of mice with $L$. major parasites plus $P$. papatasi SGS converted C57BL/6 mice - naturally resistant to $L$. major infection - into a non-healing phenotype. This outcome was associated with an increase in Th2-related cytokines such as IL-4 and IL-5. CBA mice co-inoculated with L. major parasites and $P$. papatasi SGS also upregulated expression of IL-4 and reduced production of IFN- $\gamma$, IL-12, and iNOS (8), promoting parasite proliferation. Following these observations, a series of studies further explored mechanisms involving enhanced Leishmania infection in the presence of sand-fly SGS: upon co-inoculation of L. amazonensis plus L. longipalpis SGS, larger lesions developed and were associated with elevated IL-10 production by draining lymph node cells stimulated in vitro with SGS (9). IL-10 suppresses effector functions of monocytes and macrophages and $\mathrm{NO}$ and $\mathrm{H}_{2} \mathrm{O}_{2}$ production (10), molecules that promote Leishmania killing. Moreover, L. longipalpis SGS recruited macrophages in vitro, promoting parasite survival and proliferation (11), an effect dependent on production of CCL2 (12). This observation was later confirmed in vivo following exposure of mice to L. longipalpis bites (13) or stimulation of the peritoneal cavity with $L$. major plus L. longipalpis SGS (14), which also resulted in IL-10 production.

In a mouse model of OVA-induced peritonitis, pre-treatment with $L$. longipalpis SGS reduced neutrophil recruitment by inhibiting production of TNF- $\alpha$ and IL-1b (15). P. papatasi or P. duboscqi SGS also reduced MHC Class II expression by dendritic cells and induced IL-10 and Prostaglandin $\mathrm{E}_{2}\left(\mathrm{PGE}_{2}\right)$ production (16). Intraperitoneal injection of $L$. longipalpis $S G S$ again increased the production of $\mathrm{PGE}_{2}$ and Leukotriene $\mathrm{B}_{4}\left(\mathrm{LTB}_{4}\right)$ and, in parallel, 
Table 1 | Clinical forms, main reservoirs, and sand-fly vectors of various Leishmania species

\begin{tabular}{llll}
\hline Leishmania species & Usual clinical forms & Main reservoirs & Vector sand-fly species \\
\hline Leishmania infantum chagasi & $\mathrm{VL}$ & $\begin{array}{l}\text { Dogs } \\
\text { Humans }\end{array}$ & Lutzomyia longipalpis, Lutzomyia evansi \\
Leishmania infantum & $\mathrm{VL}, \mathrm{CL}$ & Dogs & Papatasi pernicious, Papatasi ariasi, Papatasi tobbi, Papatasi neglectus \\
Leishmania donovani & $\mathrm{VL}$ & Humans & Papatasi argentipes, Papatasi orientalis, Papatasi martini \\
Leishmania tropica & $\mathrm{CL}$ & Humans & Papatasi sergenti \\
Leishmania major & $\mathrm{CL}$ & Rodents & Papatasi papatasi, Papatasi duboscqi, Papatasi salehi, Papatasi bergeroti \\
Leishmania braziliensis & $\mathrm{CL}, \mathrm{ML}$ & Dogs & Lutzomyia intermedia, Lutzomyia whitmani, Lutzomyia migonei, Lutzomyia \\
& & Humans & wellcomei, Lutzomyia ovallesi \\
Leishmania amazonensis & $\mathrm{CL}, \mathrm{DCL}$ & Rodents & Lutzomyia flaviscutellata \\
Leishmania guyanensis & $\mathrm{CL}, \mathrm{ML}$ & $\begin{array}{l}\text { Rodsupials } \\
\text { Rodents }\end{array}$ & Lutzomyia umbratilis, Lutzomyia anduzei, Lutzomyia whitmani \\
Leishmania mexicana & $\mathrm{CL}, \mathrm{DCL}$ & Rodents & Lutzomyia olmeca olmeca, Lutzomyia shannoni, Lutzomyia diabolica
\end{tabular}

VL, visceral leishmaniasis; CL, cutaneous leishmaniasis; ML, mucosal leishmaniasis; DCL, diffuse cutaneous leishmaniasis.

triggered the formation of lipid bodies (17). Indeed, $\mathrm{PGE}_{2}$ has been implicated in macrophage infection with Leishmania (18), suggesting that lipid mediators may be another parasite strategy to escape killing and establish infection. Of note, salivary molecules also modulate the function of neutrophils: L. longipalpis SGS triggers neutrophil apoptosis shown by caspase activation and expression of FasL (19) and were associated with increased parasite survival, an effect counteracted by a caspase inhibitor.

Maxadilan, a potent vasodilator, was the first molecule identified in sand-fly saliva $(20,21)$. It inhibits proliferation of mouse lymphocytes in vitro (22) and decreases TNF- $\alpha$ production both in vivo (23) and in lipopolysaccharide-treated mouse macrophages (24). Maxadilan alone exacerbated $L$. major infection to the same degree as whole SGS (25) due to its capacity to upregulate the production of IL-10 and TGF- $\beta$ and, in parallel, suppress IL-12p40, TNF- $\alpha$, and NO production (26). Employing a model of CollagenInduced Arthritis (CIA), Carregaro et al. (27), showed that $P$. papatasi SGS administered daily attenuated disease severity, an effect associated with adenosine and $5^{\prime}$ AMP (28), both of which are present at pharmacologic levels within sand-fly saliva. LJM11, a protein present in L. longipalpis SGS, prevented neutrophil migration triggered by antigen challenge in OVA-immunized mice (29). In parallel, TNF- $\alpha$ expression was reduced and IL-10 secretion was increased. Collectively, these results highlight the possibility of exploring salivary molecules in therapy against inflammatory diseases. Indeed, both Maxadilan and P. papatasi SGS decreased IFN- $\gamma$ and IL-12p40 production by human Peripheral Blood Mononuclear Cells (PBMCs) and increased IL-6 secretion in vitro (30). Treatment of lipopolysaccharide-stimulated human monocytes with $L$. longipalpis saliva confirmed its ability to decrease TNF- $\alpha$ production whereas differentiation of monocyte-derived dendritic cells in the presence of SGS inhibited expression of co-stimulatory molecules (31).

\section{SALIVARY MOLECULES AS VACCINE CANDIDATES?}

Following the observation that mice pre-exposed to $P$. papatasi SGS were protected against a challenge infection (7), a possibility emerged that a raised immune response to saliva could counteract its "exacerbative" properties and, hence, confer protection against disease. Indeed, mice repeatedly exposed to uninfected sand flies mounted an anti-saliva immune response that prevented lesion development (32). Authors associated this outcome with the development of a Delayed-Type Hypersensitivity (DTH) reaction and with IFN- $\gamma$ production, the latter acting as the hallmark cytokine associated with protection against Leishmania. Soon after, PpSP15 was identified in P. papatasi saliva, and mice immunized with the corresponding DNA plasmid were protected against a challenge infection with L. major (33). Importantly, B cell-deficient mice were also protected, suggesting that antibodies were not required for protection.

Similarly, immunization with L. longipalpis LJM19 protected against infection by Leishmania infantum chagasi, in a model of Visceral Leishmaniasis (VL) (34). Again, protection correlated with a high IFN- $\gamma$ :TGF- $\beta$ ratio and with elevated iNOS expression in the liver of challenged hamsters. In dogs, the main reservoirs of VL in Latin America, immunization with two other proteins found in L. longipalpis saliva - namely LJM17 or LJM143 - followed by exposure to sand-fly bites led to enhanced IL-12 and IFN- $\gamma$ production (35). Additionally, lymphocytes from immunized dogs effectively killed parasites in vitro. In a recent study, mice immunized with recombinant LJM11, present in L. longipalpis saliva, in the absence of an adjuvant, were challenged by L. major-infected sand-fly bites (36). Authors detected IFN- $\gamma$ being produced in response to LJM11 vaccination, which correlated with decreased numbers of parasites. Collectively, these studies strengthen the concept that anti-saliva immunity can be exploited in the context of Leishmania vaccine development. 
In fact, the combination of a salivary molecule with a Leishmania antigen for vaccine development has been pursued in different experimental models. Immunization of hamsters with DNA plasmids encoding LJM19, present in L. longipalpis saliva, plus KMP-11 [a Leishmania-derived candidate molecule for vaccine development (37)] reduced the parasite load after a challenge with L. infantum chagasi (38). This effect was similar to that observed upon immunization with LJM19 or with KMP-11 alone. Immunization of hamsters with the same DNA plasmid coding for LJM19 also prevented disease development following challenge with Leishmania braziliensis plus Lutzomyia intermedia (a vector for L. braziliensis) (see Table 1) SGS, expanding the possibility of using single salivary molecules to induce immunity to disease caused by different species of Leishmania (39). Actually, immunization with L. longipalpis SGS resulted in an expansion of $\mathrm{CD}^{+}{ }^{+}$and $\mathrm{CD}{ }^{+}{ }^{-} \mathrm{T}$ cells that secrete IFN- $\gamma$ and lead to reduced $L$. braziliensis infection in mice (40). Collectively, these studies point that immunization with certain sand-fly salivary components induces the Th1-biased immune response needed to control infection by Leishmania, currently reviewed elsewhere (41).

One major criticism to the works cited above is that animals were challenged with SGS and Leishmania by needle inoculation and were not submitted to the stringent conditions of natural transmission of Leishmania, that is, the sand-fly bite. Real-time microscopy showed that sand-fly biting at a dermal site in the mouse recruits a massive influx of neutrophils (42). Additionally, L. major parasites remained viable following phagocytosis by invading neutrophils, hinting at an immune evasion strategy to ascertain infection. Therefore, there is a pressing need to test vaccine candidates in a "real life" scenario, i.e., challenge immunized mice by bites of infected sand flies. This was the context in which Gomes et al. evaluated whether vaccination with KSAC (43) or L110f (44) - two candidates for a leishmaniasis vaccine-conferred protection against L. major transmission by sand-fly bites (45). Following sand-fly challenge, only KSAC plus GLA-SE (a synthetic TLR-4 agonist employed as adjuvant)-immunized mice showed a significant reduction of parasite number, whereas parasite levels in L110f-immunized mice were not significantly different from controls. Protection in KSAC-immunized mice correlated with IFN- $\gamma$-secreting CD4 ${ }^{+}$T cells as seen in another study in which mice were immunized with recombinant $L$. donovani superoxide dismutase B1 plus GLA-SE (46). These results suggest that vaccine candidates that perform well against live Leishmania infection may be further investigated in experiments involving challenge by sand-fly biting.

Moreover, following exposure to infected sand flies, mice that spontaneously healed a primary infection by L. major displayed a significantly lower parasite load and higher percentage of IFN$\gamma$-secreting $\mathrm{CD}^{+} \mathrm{T}$ cells compared with mice immunized with KSAC plus adjuvant (47). Indeed, healed mice are resistant to parasite transmission by sand flies (48), and this was associated with rapid mobilization of $\mathrm{CD} 4^{+} \mathrm{T}$ cells specific to Leishmania to the challenge site, hampering establishment of disease. Although these observations highlight the need to pursue studies with infected sand flies, it must be emphasized that this possibility is currently restricted to few laboratories in the world.

\section{THE DISTINGUISHED CASE OF L. INTERMEDIA, A VECTOR} FOR L. BRAZILIENSIS IN BRAZIL

Early studies showed that L. braziliensis infection was enhanced in the presence of sand-fly saliva (49-52). From these observations, the hypothesis that pre-exposure to sand-fly saliva would modify the course of $L$. braziliensis infection was investigated. Surprisingly, mice repeatedly inoculated with $L$. intermedia SGS were not protected but rather showed enhanced disease (53). Moreover, we observed that in an area endemic for L. braziliensis, Cutaneous Leishmaniasis (CL) patients displayed higher anti-saliva IgG responses compared with those with a cellular immune response to Leishmania. Human monocytes stimulated with L. intermedia SGS and exposed to L. braziliensis also upregulated TNF- $\alpha$, IL-6, and IL-8 (54), indicating the ability of $L$. intermedia saliva to alter the inflammatory milieu. Recently, however, we showed that mice immunized with a DNA plasmid coding for Linb11 - a molecule present in L. intermedia saliva - displayed reduced parasite load following infection with L. braziliensis. If one envisages a combined approach toward vaccine development encompassing parasite and salivary molecules, a careful selection must be made on the latter, as there are molecules that may protect against disease while others may enhance disease (55).

\section{IDENTIFYING THE COMPONENTS OF SAND-FLY SALIVA: THE AGE OF "SIALOMES"}

Salivary proteins have been identified in an increasing number of vectors of leishmaniasis in the last two decades (Table 2). So far, transcriptomics and proteomics allowed identification of around 40 salivary proteins such as apyrases, endonucleases, antigen 5related proteins, D7-like salivary proteins, and yellow proteins - all of which are found in several other organisms (Table 2). Apyrases hydrolyze ATP to ADP and AMP, inhibiting ADP- and collageninduced platelet aggregation (56-65). Endonucleases cleave DNA, likely decreasing blood-pool viscosity and increasing feeding success (66). In mosquito saliva, D7 salivary proteins are encoded by a multigene family related to the arthropod odorant-binding protein (OBP) superfamily and forms having either one or two OBP domains are found (67). In mosquitoes, D7 proteins act as anti-inflammatory mediators through binding of host biogenic amines, leukotrienes, and AnST-D7L1, present in Anopheles stephensi, specifically binds thromboxane $\mathrm{A}_{2}$ ( $\mathrm{TXA}_{2}$ ) (68). Last, yellow proteins bind to biogenic amines such as serotonin, catecholamine, and histamine, and this binding may dampen the proinflammatory response, blocking development of an avert reaction to the bite (69). On the other hand, families such as Lufaxin, an FXa inhibitor (70), Ppsp32-like proteins, and SL1/PpSP15-like proteins were found only in sand flies $(71,72)$. The functions of D7-like, antigen 5-like, and SL1/PpSP15 families of proteins remain to be determined.

Sialomes from L. intermedia, Lutzomyia ayacuchensis, and $L$. longipalpis - all found in the New World - express a plethora of 2to 6-kDa small peptides classified as members of the RGD family of proteins, which may function as inhibitors of platelet aggregation $(73,74)$. Salivary peptides with an RGD motif are yet to be identified in sand flies from the Old World $(73,74)$. Linb11, found in $L$. intermedia, seems specific to this species, and immunization with this molecule protected mice from L. braziliensis (73). On the other 
Table 2 | Families of most abundant Phlebotomus and Lutzomyia sand fly proteins

\begin{tabular}{|c|c|c|c|c|c|c|c|c|}
\hline \multirow[t]{2}{*}{ Species } & \multicolumn{2}{|c|}{ Vertebrates } & \multicolumn{3}{|c|}{ Insect-specific } & \multicolumn{3}{|c|}{ Sand-fly-specific } \\
\hline & Apyrase & Endonuclease & Antigen 5 & D7 & Yellow & SL1/PpSp15 & $\begin{array}{l}\text { 30-kDa } \\
\text { Family }\end{array}$ & Lufaxin \\
\hline \multicolumn{9}{|l|}{ Phlebotomus } \\
\hline P. papatasi (33) & PpSP36 & & PpSP29 & PpSP28, 30 & PpSP46, 44, 42 & PpSP15, 14, 12 & PpSP32 & PpSP34 \\
\hline $\begin{array}{l}\text { P. papatasi (73) } \\
\text { (Tunis) }\end{array}$ & PPtSP36 & & PPtSP29 & PPtSP28, 30 & PPtSP42, 44 & PPtSP12-15 & PPtSP32 & PPtSP34 \\
\hline $\begin{array}{l}\text { P. duboscai } \\
\text { (69) (Kenya) }\end{array}$ & PduK50 & & $\begin{array}{l}\text { PduK68, } \\
107\end{array}$ & $\begin{array}{l}\text { PduK34-35, } \\
69,78,103\end{array}$ & PduK04-06, 86 & $\begin{array}{l}\text { PduK01-03, 40-42, } \\
49,56-58,109\end{array}$ & $\begin{array}{l}\text { PduK45-46, } \\
83\end{array}$ & PduK70 \\
\hline $\begin{array}{l}\text { P. duboscqi } \\
\text { (69) (Mali) }\end{array}$ & PduM38-39 & & PduM48 & $\begin{array}{l}\text { PduM01, 29, } \\
46,47,77\end{array}$ & PduM10, 35 & $\begin{array}{l}\text { PduM02-03, } \\
06-07,12,31-32 \\
49-50,57-58,60 \\
62,99\end{array}$ & $\begin{array}{l}\text { PduM72, } \\
33-34,87\end{array}$ & PduM04-05 \\
\hline P. sergenti (74) & PsSP40-42 & & PsSP52 & PsSP4, 5, 7 & PsSP37, 38 & $\begin{array}{l}\text { PsSP9-11, 14-15, } \\
\text { 54-55 }\end{array}$ & PsSP44 & PsSP49 \\
\hline P. arabicus (72) & PabSP39-41 & PabSP49 & PabSP4 & $\begin{array}{l}\text { PabSP20, 54, } \\
59,84\end{array}$ & PabSP26 & PabSP2, 45, 93 & $\begin{array}{l}\text { PabSP29, } \\
30,31\end{array}$ & $\begin{array}{l}\text { PabSP32, } \\
34\end{array}$ \\
\hline P. tobbi (74) & PtSP4, 10 & & $\begin{array}{l}\text { PtSP77, } \\
78,79\end{array}$ & $\begin{array}{l}\text { PtSP42, 44, } \\
54,56-58,60\end{array}$ & $\begin{array}{l}\text { PtSP18-20, 22, } \\
26\end{array}$ & $\begin{array}{l}\text { PtSP9, 17-18, 23, } \\
31-32\end{array}$ & PtSP27-29 & PtSP66 \\
\hline $\begin{array}{l}\text { P. perniciosus } \\
\text { (67) }\end{array}$ & PpeSP01-B & PpeSP32 & PpeSP07 & $\begin{array}{l}\text { PpeSP04, 04B, } \\
10\end{array}$ & PpeSP03, 03B & PpeSP02, 09, 11 & PpeSP05 & PpeSP06 \\
\hline P. ariasi (72) & ParSP01 & ParSP10 & ParSP05 & $\begin{array}{l}\text { ParSP07, 12, } \\
16\end{array}$ & ParSP04, 04B & ParSP03, 08 & ParSP02 & ParSP09 \\
\hline $\begin{array}{l}\text { P. argentipes } \\
\text { (67) }\end{array}$ & PagSP03 & PagSP11 & PagSP05 & PagSP10, 25 & PagSP04 & $\begin{array}{l}\text { PagSP 01, 02, 07, } \\
12-13\end{array}$ & & PagSP09 \\
\hline Lutzomyia & & & & & & & & \\
\hline $\begin{array}{l}\text { L. longipalpis } \\
\text { (71) }\end{array}$ & LJL23 & LJL138 & LJL34 & LJL13 & $\begin{array}{l}\text { LJM17, LJM11, } \\
\text { LJM111 }\end{array}$ & LJM04 & & $\begin{array}{l}\text { LJL143/ } \\
\text { Lufaxin }\end{array}$ \\
\hline $\begin{array}{l}\text { L. intermedia } \\
\text { (70) }\end{array}$ & Linb-35 & Linb-46 & Linb-13 & Linb-42 & Linb-21 & Linb-7, 8, 28, 59 & & Linb-17 \\
\hline $\begin{array}{l}\text { L. ayacuchensis } \\
\text { (69) }\end{array}$ & LayS 16-21 & LayS147 & $\begin{array}{l}\text { LayS73- } \\
80\end{array}$ & LayS95-103 & $\begin{array}{l}\text { LayS22-24, 117, } \\
188\end{array}$ & LayS36, 37, 58-72 & & $\begin{array}{l}\text { LayS167, } \\
168\end{array}$ \\
\hline $\begin{array}{l}\text { Range of } \mathrm{Mw} \\
(\mathrm{kDa})\end{array}$ & $35-36$ & & 28.8-31.2 & $25.3-28.1$ & $41.5-45.2$ & $12.2-17.1$ & $22.5-34.9$ & $32.3-34.5$ \\
\hline Highlights & $\begin{array}{l}\text { Converts ATP } \\
\text { in ADP/AMP }\end{array}$ & & & & $\begin{array}{l}\text { Binds to biogenic } \\
\text { amines/protective } \\
\text { in mice }\end{array}$ & & & $\begin{array}{l}\text { Inhibition of } \\
\text { factor } \mathrm{Xa}\end{array}$ \\
\hline
\end{tabular}

hand, Maxadilan, a powerful vasodilator found in L. longipalpis (21), is apparently absent from L. intermedia and L. ayacuchensis, highlighting differences among the salivary components of different vectors. Additionally, sand flies from the Old World display more abundant transcripts coding for SL1/PpSP15-like proteins, D7-related proteins, and also for yellow proteins compared with New World sand-fly species (71).
Apart from Maxadilan, all other salivary proteins have been identified following a common approach consisting of dissection of salivary glands, isolation of mRNA, cDNA library construction, and sequencing of fewer than 2000 phages $(33,71,73,75-78)$. Bioinformatics have played a major role in identifying salivary transcripts by targeting proteins that bear a signal peptide (SignalP software) (79), thereby differentiating secretory proteins from 
structural and housekeeping transcripts. This set of techniques advanced our understanding of the most abundant salivary proteins in the absence of a sand-fly genome; however, this methodology has a bias for transcriptomic abundance and hardly detects salivary proteins of large molecular weight. One example is the Hyaluronidases - enzymes that degrade hyaluronic acid, reducing skin viscosity and facilitating blood feeding - commonly found in the venom of bees and wasps. Although hyaluronidase activity has been detected in all sand flies studied so far (78), the current approach mostly failed to detect genes coding for this protein. Hyaluronidase-coding transcripts were found in only 2 of the 13 sand-fly transcriptomes available so far (Table 2). Moreover, endonucleases were not found in P. duboscq $i$ and P. papatasi transcriptomics but their activity has been detected in salivary glands of both species (Oliveira, unpublished). Advances involving nextgeneration deep sequencing and sand-fly genome annotation will surely expand the current knowledge of salivary proteins and will allow for identification of a more complete catalog of sand-fly salivary proteins.

\section{WHAT ABOUT NATURAL EXPOSURE TO SAND FLIES IN ENDEMIC AREAS?}

Studies in areas endemic for VL in Brazil showed an association between anti-L. longipalpis antibodies and the presence of an anti-Leishmania cell-mediated immune response in humans (80). Simultaneous development of a humoral response to saliva and a cellular response to Leishmania (described by the presence of a positive DTH) (81) suggested that induction of an immune response against $L$. longipalpis SGS could facilitate development of a protective response against leishmaniasis. This notion was strengthened by the demonstration that volunteers experimentally exposed to L. longipalpis bites displayed a strong cellular immune response to $L$. longipalpis SGS characterized by IFN- $\gamma$ production and appearance of a DTH at the bite site (82). Moreover, co-culture of infected macrophages plus autologous lymphocytes in the presence of L. longipalpis SGS stimulated a recall response that significantly reduced the parasite load in vitro. In a prospective cohort study in a VL-endemic area in Brazil, the incidence of DTH to Leishmania antigen was higher among residents with anti-SGS IgG (83), leading to the hypothesis that immunity to L. longipalpis sand-fly saliva is a surrogate marker of protection against $L$. infantum chagasi infection. It is unclear whether this protective effect is due to antibodies that neutralize the "exacerbative" properties of sand-fly saliva or due to an anti-saliva cellular immune response that acts rapidly after parasite inoculation, limiting Leishmania survival in the human host.

There are, as expected, limitations to using SGS in epidemiologic studies, as sand flies need either to be reared in laboratory colonies or to be actively collected in the field. To this end, the "sialomes" discussed above allowed the identification, cloning, and expression of recombinant salivary proteins from distinct sand-fly species. Employing recombinant salivary proteins, Teixeira et al. showed that foxes and dogs - reservoirs for VL - as well as individuals from an endemic area in Brazil recognize LJM11 and LJM17, present in L. longipalpis saliva (84). These results were validated in a sample of 1077 individuals, and detection levels improved significantly when the two proteins were used in combination (85).
A prospective study conducted in Tunisia with a cohort of 200 children showed that IgG antibodies (primarily IgG4) against $P$. papatasi SGS were associated with an increased risk of CL caused by $L$. major (86). In a subsequent study, recombinant PpSP32 was described as the immunodominant antigen in the humoral response, acting as a marker of sand-fly exposure (87). In Turkey, patients from a CL-endemic area where Leishmania tropica is prevalent displayed significantly higher anti-Phlebotomus sergenti IgG levels when compared with healthy individuals from the same area (88). These data suggest that saliva can be used for monitoring exposure of humans to sand flies. Indeed, Clements et al. found a correlation between antibodies to Phlebotomus argentipes saliva and vector density (89). Chickens are also useful at monitoring exposure to sand flies, as they develop specific anti-SGS IgY and, therefore, can be employed as sentinel animals (90).

In Mali, where P. duboscqi is prevalent, three profiles of cellular immune response were observed: while 23 and $25 \%$ of individuals developed a Th1 or Th2-polarized immune response, respectively, $52 \%$ displayed a mixed Th1/Th2 response to salivary molecules (91). Analysis of biopsy samples in a subset of anti-saliva DTH-reactive individuals revealed the presence of lymphocytes, macrophages, and IFN- $\gamma$ production, which were associated with the Th1 response. These results suggest that individuals presenting a Th1-polarized response would be protected against CL, as seen in the experimental models of infection (92), whereas individuals with Th2 immune response remain susceptible to disease. Prospective studies evaluating outcome of infection in these polarized individuals are necessary to further address this hypothesis. On the contrary, in Tunisia, individuals naturally exposed to $P$. papatasi bites displayed antigen-specific IL-10 production by $\mathrm{CD}^{+} \mathrm{T}$ cells in vitro, while activated $\mathrm{CD}^{+}{ }^{+} \mathrm{T}$ lymphocytes cultured in the absence of $\mathrm{CD}^{+} \mathrm{T}$ cells were able to produce IFN- $\gamma$ (93). The authors suggested that IL-10 production favors L. major proliferation at the moment of transmission by infected sand flies.

\section{PERSPECTIVES}

Many factors represent challenges to the study of leishmaniasis, from the shortage of funding to climate change and population displacements. Nevertheless, the almost ubiquitous use of needle infections - bypassing the natural transmission process through an infected sand-fly bite - is a serious limitation. We face the risk of studying a model of disease too disparate from leishmanial disease occurring in the field, thus leading to unsuccessful vaccines and treatments. There is the need to support the establishment of more sand-fly colonies and standardization of techniques for sand-fly infection among the leishmaniasis community. Moreover, more prospective studies in humans from endemic areas are indispensable to better understand the basis of protective human immune responses to Leishmania and sand-fly saliva.

\section{AUTHOR CONTRIBUTIONS}

All authors have discussed and written the manuscript.

\section{ACKNOWLEDGMENTS}

This work was supported by the Intramural Research Program of the Division of Intramural Research, National Institute of Allergy and Infectious Diseases, National Institutes of Health. We thank 
Brenda Rae Marshall, DPSS, NIAID, for editing. Because Fabiano Oliveira is a government employe and this is a government work, the work is in the public domain in the U.S. Notwithstanding any other agreements, the NIH reserves the right to provide the work to PubMed Central for display and use by the public, and PubMed Central may tag or modify the work consistent with its customary practices. You can establish rights outside of the U.S. subject to a government use license.

\section{REFERENCES}

1. Ribeiro JM. Role of saliva in blood-feeding by arthropods. Annu Rev Entomol (1987) 32:463-78. doi:10.1146/annurev.en.32.010187.002335

2. Titus RG, Ribeiro JM. Salivary gland lysates from the sand fly Lutzomyia longipalpis enhance Leishmania infectivity. Science (1988) 239:1306-8. doi:10.1126/ science. 3344436

3. Theodos C, Ribeiro J, Titus R. Analysis of enhancing effect of sand fly saliva on Leishmania infection in mice. Infect Immun (1991) 59:1592-8.

4. Anjili CO, Mbati PA, Mwangi RW, Githure JI, Olobo JO, Robert LL, et al. The chemotactic effect of Phlebotomus duboscqi (diptera: psychodidae) salivary gland lysates to murine monocytes. Acta Trop (1995) 60:97-100. doi:10.1016/0001706X(95)00112-R

5. Hall LR, Titus RG. Sand fly vector saliva selectively modulates macrophage functions that inhibit killing of Leishmania major and nitric oxide production. J Immunol (1995) 155:3501-6.

6. Waitumbi J, Warburg A. Phlebotomus papatasi saliva inhibits protein phosphatase activity and nitric oxide production by murine macrophages. Infect Immun (1998) 66:1534-7.

7. Belkaid Y, Kamhawi S, Modi G, Valenzuela J, Noben-Trauth N, Rowton E, et al. Development of a natural model of cutaneous leishmaniasis: powerful effects of vector saliva and saliva preexposure on the long-term outcome of Leishmania major infection in the mouse ear dermis. J Exp Med (1998) 188:1941-53. doi:10.1084/jem.188.10.1941

8. Mbow ML, Bleyenberg JA, Hall LR, Titus RG. Phlebotomus papatasi sand fly salivary gland lysate down-regulates a Th1, but up-regulates a Th2, response in mice infected with Leishmania major. J Immunol (1998) 161:5571-7.

9. Norsworthy N, Sun J, Elnaiem D, Lanzaro G, Soong L. Sand fly saliva enhances Leishmania amazonensis infection by modulating interleukin-10 production. Infect Immun (2004) 72:1240-7. doi:10.1128/IAI.72.3.1240-1247.2004

10. Moore KW, de Waal Malefyt R, Coffman RL, O'Garra A. Interleukin-10 and the interleukin-10 receptor. Annu Rev Immunol (2001) 19:683-765. doi:10.1146/ annurev.immunol.19.1.683

11. Zer R, Yaroslavski I, Rosen L, Warburg A. Effect of sand fly saliva on Leishmania uptake by murine macrophages. Int J Parasitol (2001) 31:810-4. doi:10.1016/ S0020-7519(01)00190-4

12. Teixeira C, Teixeira M, Gomes R, Santos C, Andrade B, Raffaele-Netto I, et al. Saliva from Lutzomyia longipalpis induces CC chemokine ligand 2/monocyte chemoattractant protein-1 expression and macrophage recruitment 1 . J Immunol (2005) 175:8346-53.

13. Silva F, Gomes R, Prates D, Miranda JC, Andrade B, Barral-Netto M, et al. Inflammatory cell infiltration and high antibody production in BALB/c mice caused by natural exposure to Lutzomyia longipalpis bites. Am J Trop Med Hyg (2005) 72:94-8.

14. Monteiro MC, Lima HC, Souza AA, Titus RG, Romao PR, Cunha FQ. Effect of Lutzomyia longipalpis salivary gland extracts on leukocyte migration induced by Leishmania major. Am J Trop Med Hyg (2007) 76:88-94.

15. Monteiro MC, Nogueira LG, Almeida Souza AA, Ribeiro JM, Silva JS, Cunha FQ. Effect of salivary gland extract of Leishmania vector, Lutzomyia longipalpis, on leukocyte migration in OVA-induced immune peritonitis. Eur J Immunol (2005) 35:2424-33. doi:10.1002/eji.200526160

16. Carregaro V, Valenzuela JG, Cunha TM, Verri WA Jr, Grespan R, Matsumura G, et al. Phlebotomine salivas inhibit immune inflammation-induced neutrophil migration via an autocrine DC-derived PGE2/IL-10 sequential pathway. J Leukoc Biol (2008) 84:104-14. doi:10.1189/jlb.1107797

17. Araujo-Santos T, Prates DB, Andrade BB, Nascimento DO, Clarencio J, Entringer $\mathrm{PF}$, et al. Lutzomyia longipalpis saliva triggers lipid body formation and prostaglandin E(2) production in murine macrophages. PLoS Negl Trop Dis (2010) 4:e873. doi:10.1371/journal.pntd.0000873
18. Lonardoni MV, Barbieri CL, Russo M, Jancar S. Modulation of Leishmania (L.) amazonensis growth in cultured mouse macrophages by prostaglandins and platelet activating factor. Mediators Inflamm (1994) 3:137-41. doi:10.1155/ S0962935194000177

19. Prates DB, Araújo-Santos T, Luz NF, Andrade BB, França-Costa J, Afonso L, et al. Lutzomyia longipalpis saliva drives apoptosis and enhances parasite burden in neutrophils. J Leukoc Biol (2011) 90(3):575-82. doi:10.1189/jlb.0211105

20. Ribeiro JM. Vector saliva and its role in parasite transmission. Exp Parasitol (1989) 69:104-6. doi:10.1016/0014-4894(89)90177-X

21. Lerner EA, Ribeiro JM, Nelson RJ, Lerner MR. Isolation of maxadilan, a potent vasodilatory peptide from the salivary glands of the sand fly Lutzomyia longipalpis. J Biol Chem (1991) 266:11234-6.

22. Qureshi AA, Asahina A, Ohnuma M, Tajima M, Granstein RD, Lerner EA. Immunomodulatory properties of maxadilan, the vasodilator peptide from sand fly salivary gland extracts. Am J Trop Med Hyg (1996) 54:665-71.

23. Bozza M, Soares MB, Bozza PT, Satoskar AR, Diacovo TG, Brombacher F, et al. The PACAP-type I receptor agonist maxadilan from sand fly saliva protects mice against lethal endotoxemia by a mechanism partially dependent on IL10. Eur J Immunol (1998) 28:3120-7. doi:10.1002/(SICI)1521-4141(199810)28: $10<3120:: A I D-I M M U 3120>3.0 . C O ; 2-3$

24. Soares MB, Titus RG, Shoemaker CB, David JR, Bozza M. The vasoactive peptide maxadilan from sand fly saliva inhibits TNF-alpha and induces IL-6 by mouse macrophages through interaction with the pituitary adenylate cyclase-activating polypeptide (PACAP) receptor. J Immunol (1998) 160:1811-6.

25. Morris RV, Shoemaker CB, David JR, Lanzaro GC, Titus RG. Sandfly maxadilan exacerbates infection with Leishmania major and vaccinating against it protects against L. major infection. J Immunol (2001) 167:5226-30.

26. Brodie T, Smith M, Morris R, Titus R. Immunomodulatory effects of the Lutzomyia longipalpis salivary gland protein maxadilan on mouse macrophages. Infect Immun (2007) 75:2359-65. doi:10.1128/IAI.01812-06

27. Carregaro V, Sa-Nunes A, Cunha TM, Grespan R, Oliveira CJ, Lima-Junior DS, et al. Nucleosides from Phlebotomus papatasi salivary gland ameliorate murine collagen-induced arthritis by impairing dendritic cell functions. J Immunol (2011) 187:4347-59. doi:10.4049/jimmunol.1003404

28. Ribeiro JM, Katz O, Pannell LK, Waitumbi J, Warburg A. Salivary glands of the sand fly Phlebotomus papatasi contain pharmacologically active amounts of adenosine and 5'-AMP. J Exp Biol (1999) 202:1551-9.

29. Grespan R, Lemos HP, Carregaro V, Verri WA Jr, Souto FO, de Oliveira CJ, et al. The protein LJM 111 from Lutzomyia longipalpis salivary gland extract (SGE) accounts for the SGE-inhibitory effects upon inflammatory parameters in experimental arthritis model. Int Immunopharmacol (2012) 12:603-10. doi:10.1016/j.intimp.2012.02.004

30. Rogers KA, Titus RG. Immunomodulatory effects of maxadilan and Phlebotomus papatasi sand fly salivary gland lysates on human primary in vitro immune responses. Parasite Immunol (2003) 25:127-34. doi:10.1046/j.1365-3024.2003. 00623.x

31. Costa DJ, Favali C, Clarencio J, Afonso L, Conceicao V, Miranda JC, et al. Lutzomyia longipalpis salivary gland homogenate impairs cytokine production and costimulatory molecule expression on human monocytes and dendritic cells. Infect Immun (2004) 72:1298-305. doi:10.1128/IAI.72.3.1298-1305.2004

32. Kamhawi S. Protection against cutaneous leishmaniasis resulting from bites of uninfected sand flies. Science (2000) 290:1351-4. doi:10.1126/science.290.5495. 1351

33. Valenzuela JG, Belkaid Y, Garfield MK, Mendez S, Kamhawi S, Rowton ED, et al. Toward a defined anti-Leishmania vaccine targeting vector antigens: characterization of a protective salivary protein. J Exp Med (2001) 194:331-42. doi:10.1084/jem.194.3.331

34. Gomes R, Teixeira C, Teixeira MJ, Oliveira F, Menezes MJ, Silva C, et al. Immunity to a salivary protein of a sand fly vector protects against the fatal outcome of visceral leishmaniasis in a hamster model. Proc Natl Acad Sci U S A (2008) 105:7845-50. doi:10.1073/pnas.0712153105

35. Collin N, Gomes R, Teixeira C, Cheng L, Laughinghouse A, Ward JM, et al. Sand fly salivary proteins induce strong cellular immunity in a natural reservoir of visceral leishmaniasis with adverse consequences for Leishmania. PLoS Pathog (2009) 5:e1000441. doi:10.1371/journal.ppat.1000441

36. Gomes R, Oliveira F, Teixeira C, Meneses C, Gilmore DC, Elnaiem DE, et al. Immunity to sand fly salivary protein LJM11 modulates host response to vector-transmitted Leishmania conferring ulcer-free protection. J Invest Dermatol (2012) 132:2735-43. doi:10.1038/jid.2012.205 
37. Basu R, Bhaumik S, Basu JM, Naskar K, De T, Roy S. Kinetoplastid membrane protein-11 DNA vaccination induces complete protection against both pentavalent antimonial-sensitive and -resistant strains of Leishmania donovani that correlates with inducible nitric oxide synthase activity and IL-4 generation: evidence for mixed Th1- and Th2-like responses in visceral leishmaniasis. J Immunol (2005) 174:7160-71.

38. da Silva RA, Tavares NM, Costa D, Pitombo M, Barbosa L, Fukutani K, et al. DNA vaccination with KMP11 and Lutzomyia longipalpis salivary protein protects hamsters against visceral leishmaniasis. Acta Trop (2011) 120:185-90. doi:10.1016/j.actatropica.2011.08.007

39. Tavares NM, Silva RA, Costa DJ, Pitombo MA, Fukutani KF, Miranda JC, et al. Lutzomyia longipalpis saliva or salivary protein LJM19 protects against Leishmania braziliensis and the saliva of its vector, Lutzomyia intermedia. PLoS Negl Trop Dis (2011) 5:e1169. doi:10.1371/journal.pntd.0001169

40. Carregaro V, Costa DL, Brodskyn C, Barral AM, Barral-Netto M, Cunha FQ, et al. Dual effect of Lutzomyia longipalpis saliva on Leishmania braziliensis infection is mediated by distinct saliva-induced cellular recruitment into BALB/c mice ear. BMC Microbiol (2013) 13:102. doi:10.1186/1471-2180-13-102

41. Gomes R, Oliveira F. The immune response to sand fly salivary proteins and its influence on Leishmania immunity. Front Immunol (2012) 3:110. doi:10.3389/fimmu.2012.00110

42. Peters N, Egen J, Secundino N, Debrabant A, Kimblin N, Kamhawi S, et al. In vivo imaging reveals an essential role for neutrophils in leishmaniasis transmitted by sand flies. Science (2008) 321:970-4. doi:10.1126/science.1159194

43. Goto Y, Bhatia A, Raman VS, Liang H, Mohamath R, Picone AF, et al. KSAC, the first defined polyprotein vaccine candidate for visceral leishmaniasis. Clin Vaccine Immunol (2011) 18:1118-24. doi:10.1128/CVI.05024-11

44. Bertholet S, Goto Y, Carter L, Bhatia A, Howard RF, Carter D, et al. Optimized subunit vaccine protects against experimental leishmaniasis. Vaccine (2009) 27:7036-45. doi:10.1016/j.vaccine.2009.09.066

45. Gomes R, Teixeira C, Oliveira F, Lawyer PG, Elnaiem DE, Meneses C, et al. KSAC, a defined Leishmania antigen, plus adjuvant protects against the virulence of $L$. major transmitted by its natural vector Phlebotomus duboscqi. PLoS Negl Trop Dis (2012) 6:e1610. doi:10.1371/journal.pntd.0001610

46. Daifalla NS, Bayih AG, Gedamu L. Leishmania donovani recombinant iron superoxide dismutase $\mathrm{B} 1$ protein in the presence of TLR-based adjuvants induces partial protection of BALB/c mice against Leishmania major infection. Exp Parasitol (2012) 131:317-24. doi:10.1016/j.exppara.2012.05.002

47. Peters NC, Bertholet S, Lawyer PG, Charmoy M, Romano A, Ribeiro-Gomes FL, et al. Evaluation of recombinant Leishmania polyprotein plus glucopyranosyl lipid A stable emulsion vaccines against sand fly-transmitted Leishmania major in C57BL/6 mice. J Immunol (2012) 189:4832-41. doi:10.4049/jimmunol. 1201676

48. Peters NC, Kimblin N, Secundino N, Kamhawi S, Lawyer P, Sacks DL. Vector transmission of Leishmania abrogates vaccine-induced protective immunity. PLoS Pathog (2009) 5:e1000484. doi:10.1371/journal.ppat.1000484

49. Samuelson J, Lerner E, Tesh R, Titus R. A mouse model of Leishmania braziliensis braziliensis infection produced by coinjection with sand fly saliva. J Exp Med (1991) 173:49-54. doi:10.1084/jem.173.1.49

50. Lima H, Titus R. Effects of sand fly vector saliva on development of cutaneous lesions and the immune response to Leishmania braziliensis in BALB/c mice. Infect Immun (1996) 64:5442.

51. Donnelly KB, Lima HC, Titus RG. Histologic characterization of experimental cutaneous leishmaniasis in mice infected with Leishmania braziliensis in the presence or absence of sand fly vector salivary gland lysate. J Parasitol (1998) 84:97-103. doi:10.2307/3284537

52. Bezerra H, Teixeira M. Effect of Lutzomyia whitmani (diptera: psychodidae) salivary gland lysates on Leishmania (Viannia) braziliensis infection in BALB/c mice. Mem Inst Oswaldo Cruz (2001) 96:349-51. doi:10.1590/S007402762001000300011

53. de Moura TR, Oliveira F, Novais FO, Miranda JC, Clarencio J, Follador I, et al. Enhanced Leishmania braziliensis infection following pre-exposure to sandfly saliva. PLoS Negl Trop Dis (2007) 1:e84. doi:10.1371/journal.pntd. 0000084

54. Menezes MJ, Costa DJ, Clarencio J, Miranda JC, Barral A, Barral-Netto $\mathrm{M}$, et al. Immunomodulation of human monocytes following exposure to Lutzomyia intermedia saliva. BMC Immunol (2008) 9:12. doi:10.1186/14712172-9- 12
55. Oliveira F, Lawyer PG, Kamhawi S, Valenzuela JG. Immunity to distinct sand fly salivary proteins primes the anti-Leishmania immune response towards protection or exacerbation of disease. PLoS Negl Trop Dis (2008) 2:e226. doi:10.1371/journal.pntd.0000226

56. Ribeiro JM, Sarkis JJ, Rossignol PA, Spielman A. Salivary apyrase of Aedes aegypti: characterization and secretory fate. Comp Biochem Physiol B (1984) 79:81-6.

57. Sarkis JJ, Guimaraes JA, Ribeiro JM. Salivary apyrase of Rhodnius prolixus. Kinetics and purification. Biochem J (1986) 233:885-91.

58. Ribeiro JM, Vaughan JA, Azad AF. Characterization of the salivary apyrase activity of three rodent flea species. Comp Biochem Physiol B (1990) 95:215-9.

59. Ribeiro JM, Endris TM, Endris R. Saliva of the soft tick, Ornithodoros moubata, contains anti-platelet and apyrase activities. Comp Biochem Physiol A Comp Physiol (1991) 100:109-12. doi:10.1016/0300-9629(91)90190-N

60. Champagne DE, Smartt CT, Ribeiro JM, James AA. The salivary gland-specific apyrase of the mosquito Aedes aegypti is a member of the 5'-nucleotidase family. Proc Natl Acad Sci U S A (1995) 92:694-8. doi:10.1073/pnas.92.3.694

61. Mathews GV, Sidjanski S, Vanderberg JP. Inhibition of mosquito salivary gland apyrase activity by antibodies produced in mice immunized by bites of Anopheles stephensi mosquitoes. Am J Trop Med Hyg (1996) 55:417-23.

62. Mans BJ, Gaspar AR, Louw AI, Neitz AW. Apyrase activity and platelet aggregation inhibitors in the tick Ornithodoros savignyi (Acari: Argasidae). Exp Appl Acarol (1998) 22:353-66. doi:10.1023/A:1024517209621

63. Lombardo F, Di Cristina M, Spanos L, Louis C, Coluzzi M, Arca B. Promoter sequences of the putative Anopheles gambiae apyrase confer salivary gland expression in Drosophila melanogaster. J Biol Chem (2000) 275:23861-8. doi:10.1074/jbc.M909547199

64. Valenzuela JG, Belkaid Y, Rowton E, Ribeiro JM. The salivary apyrase of the blood-sucking sand fly Phlebotomus papatasi belongs to the novel Cimex family of apyrases. J Exp Biol (2001) 204:229-37.

65. Reno HE, Novak RJ. Characterization of apyrase-like activity in Ochlerotatus triseriatus, Ochlerotatus hendersoni, and Aedes aegypti. Am J Trop Med Hyg (2005) 73:541-5.

66. Calvo E, Ribeiro JM. A novel secreted endonuclease from Culex quinquefasciatus salivary glands. J Exp Biol (2006) 209:2651-9. doi:10.1242/jeb.02267

67. Calvo E, Mans BJ, Ribeiro JM, Andersen JF. Multifunctionality and mechanism of ligand binding in a mosquito antiinflammatory protein. Proc Natl Acad Sci U S A (2009) 106:3728-33. doi:10.1073/pnas.0813190106

68. Alvarenga PH, Francischetti IM, Calvo E, Sa-Nunes A, Ribeiro JM, Andersen JF. The function and three-dimensional structure of a thromboxane A2/cysteinyl leukotriene-binding protein from the saliva of a mosquito vector of the malaria parasite. PLoS Biol (2010) 8:e1000547. doi:10.1371/journal.pbio.1000547

69. Xu X, Oliveira F, Chang BW, Collin N, Gomes R, Teixeira C, et al. Structure and function of a "yellow" protein from saliva of the sand fly Lutzomyia longipalpis that confers protective immunity against Leishmania major infection. J Biol Chem (2011) 286:32383-93. doi:10.1074/jbc.M111.268904

70. Collin N, Assumpcao TC, Mizurini DM, Gilmore DC, Dutra-Oliveira A, Kotsyfakis $\mathrm{M}$, et al. Lufaxin, a novel factor Xa inhibitor from the salivary gland of the sand fly Lutzomyia longipalpis blocks protease-activated receptor 2 activation and inhibits inflammation and thrombosis in vivo. Arterioscler Thromb Vasc Biol (2012) 32:2185-98. doi:10.1161/ATVBAHA.112.253906

71. Anderson JM, Oliveira F, Kamhawi S, Mans BJ, Reynoso D, Seitz AE, et al. Comparative salivary gland transcriptomics of sandfly vectors of visceral leishmaniasis. BMC Genomics (2006) 7:52. doi:10.1186/1471-2164-7-52

72. Ribeiro JM, Mans BJ, Arca B. An insight into the sialome of blood-feeding Nematocera. Insect Biochem Mol Biol (2010) 40:767-84. doi:10.1016/j.ibmb.2010.08. 002

73. de Moura TR, Oliveira F, Carneiro MW, Miranda JC, Clarencio J, BarralNetto M, et al. Functional transcriptomics of wild-caught Lutzomyia intermedia salivary glands: identification of a protective salivary protein against Leishmania braziliensis infection. PLoS Negl Trop Dis (2013) 7:e2242. doi:10.1371/journal. pntd.0002242

74. Kato H, Jochim RC, Gomez EA, Uezato H, Mimori T, Korenaga M, et al. Analysis of salivary gland transcripts of the sand fly Lutzomyia ayacuchensis, a vector of Andean-type cutaneous leishmaniasis. Infect Genet Evol (2013) 13:56-66. doi:10.1016/j.meegid.2012.08.024

75. Valenzuela JG, Garfield M, Rowton ED, Pham VM. Identification of the most abundant secreted proteins from the salivary glands of the sand fly Lutzomyia 
longipalpis, vector of Leishmania chagasi. J Exp Biol (2004) 207:3717-29. doi:10.1242/jeb.01185

76. Hostomska J, Volfova V, Mu J, Garfield M, Rohousova I, Volf P, et al. Analysis of salivary transcripts and antigens of the sand fly Phlebotomus arabicus. BMC Genomics (2009) 10:282. doi:10.1186/1471-2164-10-282

77. Abdeladhim M, Jochim RC, Ben Ahmed M, Zhioua E, Chelbi I, Cherni S, et al. Updating the salivary gland transcriptome of Phlebotomus papatasi (Tunisian strain): the search for sand fly-secreted immunogenic proteins for humans. PLoS One (2012) 7:e47347. doi:10.1371/journal.pone.0047347

78. Rohousova I, Subrahmanyam S, Volfova V, Mu J, Volf P, Valenzuela JG, et al. Salivary gland transcriptomes and proteomes of Phlebotomus tobbi and Phlebotomus sergenti, vectors of leishmaniasis. PLoS Negl Trop Dis (2012) 6:e1660. doi:10.1371/journal.pntd.0001660

79. Petersen TN, Brunak S, Von Heijne G, Nielsen H. SignalP 4.0: discriminating signal peptides from transmembrane regions. Nat Methods (2011) 8:785-6. doi:10.1038/nmeth.1701

80. Barral A, Honda E, Caldas A, Costa J, Vinhas V, Rowton ED, et al. Human immune response to sand fly salivary gland antigens: a useful epidemiological marker? Am J Trop Med Hyg (2000) 62:740-5.

81. Gomes RB, Brodskyn C, de Oliveira CI, Costa J, Miranda JC, Caldas A, et al. Seroconversion against Lutzomyia longipalpis saliva concurrent with the development of anti-Leishmania chagasi delayed-type hypersensitivity. J Infect Dis (2002) 186:1530-4. doi:10.1086/344733

82. Vinhas V, Andrade BB, Paes F, Bomura A, Clarencio J, Miranda JC, et al. Human anti-saliva immune response following experimental exposure to the visceral leishmaniasis vector, Lutzomyia longipalpis. Eur J Immunol (2007) 37:3111-21. doi:10.1002/eji.200737431

83. Aquino DM, Caldas AJ, Miranda JC, Silva AA, Barral-Netto M, Barral A. Epidemiological study of the association between anti-Lutzomyia longipalpis saliva antibodies and development of delayed-type hypersensitivity to Leishmania antigen. Am J Trop Med Hyg (2010) 83(4):825-7. doi:10.4269/ajtmh.2010.100182

84. Teixeira C, Gomes R, Collin N, Reynoso D, Jochim R, Oliveira F, et al. Discovery of markers of exposure specific to bites of Lutzomyia longipalpis, the vector of Leishmania infantum chagasi in Latin America. PLoS Negl Trop Dis (2010) 4:e638. doi:10.1371/journal.pntd.0000638

85. Souza AP, Andrade BB, Aquino D, Entringer P, Miranda JC, Alcantara R, et al. Using recombinant proteins from Lutzomyia longipalpis saliva to estimate human vector exposure in visceral leishmaniasis endemic areas. PLoS Negl Trop Dis (2010) 4:e649. doi:10.1371/journal.pntd.0000649

86. Marzouki S, Ben Ahmed M, Boussoffara T, Abdeladhim M, Ben Aleya-Bouafif $\mathrm{N}$, Namane A, et al. Characterization of the antibody response to the saliva of Phlebotomus papatasi in people living in endemic areas of cutaneous leishmaniasis. Am J Trop Med Hyg (2011) 84:653-61. doi:10.4269/ajtmh.2011. 10-0598
87. Marzouki S, Abdeladhim M, Abdessalem CB, Oliveira F, Ferjani B, Gilmore D, et al. Salivary antigen SP32 is the immunodominant target of the antibody response to Phlebotomus papatasi bites in humans. PLoS Negl Trop Dis (2012) 6:e1911. doi:10.1371/journal.pntd.0001911

88. Rohousova I, Ozensoy S, Ozbel Y, Volf P. Detection of species-specific antibody response of humans and mice bitten by sand flies. Parasitology (2005) 130:493-9. doi:10.1017/S003118200400681X

89. Clements MF, Gidwani K, Kumar R, Hostomska J, Dinesh DS, Kumar V, et al. Measurement of recent exposure to Phlebotomus argentipes, the vector of Indian visceral leishmaniasis, by using human antibody responses to sand fly saliva. Am J Trop Med Hyg (2010) 82:801-7. doi:10.4269/aitmh.2010.09-0336

90. Soares BR, Souza AP, Prates DB, de Oliveira CI, Barral-Netto M, Miranda JC, et al. Seroconversion of sentinel chickens as a biomarker for monitoring exposure to visceral leishmaniasis. Sci Rep (2013) 3:2352. doi:10.1038/srep02352

91. Oliveira F, Traore B, Gomes R, Faye O, Gilmore DC, Keita S, et al. Delayedtype hypersensitivity to sand fly saliva in humans from a leishmaniasis-endemic area of Mali is Th1-mediated and persists to midlife. J Invest Dermatol (2013) 133:452-9. doi:10.1038/jid.2012.315

92. Sacks D, Noben-Trauth N. The immunology of susceptibility and resistance to Leishmania major in mice. Nat Rev Immunol (2002) 2:845-58. doi:10.1038/ nri933

93. Abdeladhim M, Ben Ahmed M, Marzouki S, Belhadj Hmida N, Boussoffara T, Belhaj Hamida N, et al. Human cellular immune response to the saliva of Phlebotomus papatasi is mediated by IL-10-producing CD8+ T cells and Th1-polarized CD4+ lymphocytes. PLoS Negl Trop Dis (2011) 5:e1345. doi:10.1371/journal.pntd.0001345

Conflict of Interest Statement: The authors declare that the research was conducted in the absence of any commercial or financial relationships that could be construed as a potential conflict of interest.

Received: 20 September 2013; paper pending published: 15 October 2013; accepted: 31 October 2013; published online: 19 November 2013.

Citation: Oliveira F, de Carvalho AM and de Oliveira CI (2013) Sandfly saliva-Leishmania-man: the trigger trio. Front. Immunol. 4:375. doi: 10.3389/fimmu.2013.00375

This article was submitted to Microbial Immunology, a section of the journal Frontiers in Immunology.

Copyright (๑) 2013 Oliveira, de Carvalho and de Oliveira. This is an open-access article distributed under the terms of the Creative Commons Attribution License (CC BY). The use, distribution or reproduction in other forums is permitted, provided the original author(s) or licensor are credited and that the original publication in this journal is cited, in accordance with accepted academic practice. No use, distribution or reproduction is permitted which does not comply with these terms. 